\title{
Psychological Well-Being in Awaiting-Trial Inmates: The Roles of Loneliness and Social Support
}

\author{
Philip Chukwuemeka Mefoh ${ }^{1}$, Victor Okechukwu Odo ${ }^{1}$, Michael Arinze Ezeh ${ }^{2}$, \\ Linda Ekwutosi Ezeah ${ }^{1}$ \\ ${ }^{1}$ Department of Psychology, Faculty of the Social Sciences, University of Nigeria, Nsukka, Nigeria \\ ${ }^{2}$ Department of Psychology, Faculty of Management and Social Sciences, Renaissance University, Enugu, Nigeria
}

Email address:

philip.mefoh@unn.edu.ng (P.C. Mefoh)

To cite this article:

Philip Chukwuemeka Mefoh, Victor Okechukwu Odo, Michael Arinze Ezeh, Linda Ekwutosi Ezeah. Psychological Well-Being in AwaitingTrial Inmates: The Roles of Loneliness and Social Support. Social Sciences. Vol. 5, No. 5, 2016, pp. 64-69. doi: 10.11648/j.ss.20160505.11

Received: August 6, 2016; Accepted: August 18, 2016; Published: September 12, 2016

\begin{abstract}
This research examined the roles of loneliness and social support as predictors of psychological well-being in awaiting-trial inmates. Participants were 300 awaiting-trial inmates of Enugu Prison Command. There were 200 (73.33\%) male inmates and $80(26.66 \%)$ female inmates in the sample. Their ages ranged between 18 years and 69 years (Mean age = 43.50 years; Standard Deviation $=5.21$ ). Purposive sampling method was adopted in the sample selection; and participation in the study was anonymous. Three instruments - the short-form University of California, Los Angeles loneliness scale (ULS-8), the multidimensional scale of perceived social support (MSPSS), and the psychological well-being scale (PWB-S), were used for data collection. Analysis of data was conducted with multiple regressions and correlations (MRC). Results showed that loneliness and social support were significant predictors of psychological well-being. The findings failed to confirm the first hypothesis, but confirmed the second hypothesis. Discussion highlighted the need to establish vocational training facilities and other social services in prisons to constructively engage prison inmates in meaningful tasks.
\end{abstract}

Keywords: Awaiting-Trial Inmates, Enugu Prison Command, Loneliness, Psychological Well-Being, Social Support

\section{Introduction}

The present day Nigeria presents some of the worst socioeconomic challenges of all times. Today's youths are frustrated for lack of employment opportunities, low educational attainment, little participation in decision making and low social mobility. These legitimate grievances and many more lure many young people (especially) to develop criminal tendencies. Every society has its rules and there are individuals that conform to these rules as well as those that deviate from them. The later persons are sanctioned and incarcerated in prisons $[1,16]$. The Prison institution is a penitentiary institution for re-socializing offenders to conform to society's values and to learn how to be good citizens. In Nigeria, prison inmates consist of two main categories: convicted persons serving out jail terms, and many others who are awaiting trial, but are remanded in prison custody. With the high incidence of criminality in the present day Nigeria, ranging from religious fundamentalism, terrorism, and insurgency in the North to communal conflicts, kidnappings and broad day robbery in the south, Nigerian Prisons have acute overcrowding problems. As [35] points out, "within the last ten years, more Nigerians have probably lost their lives to the frequent conflicts and other violent crimes around the country than to motor accidents and infectious diseases put together" (p. 8). With such high level of criminality, it is not surprising that prisons in Nigeria have a teeming population.

There are four principal reasons why people who contravene the law are put in prison. These are: to punish the offenders; to protect society; to prevent future crimes; and to reform or rehabilitate the offenders. The prisons may take criminals off the streets for a while, but the prison does not guarantee that the prisoner comes out of prison being a better individual. Thus, the present study is an attempt to draw stakeholders' attention to the psychosocial needs of the inmate who is first and foremost a human person. The idea of reforming an offender should not just be focused only on 
building more prisons, improving the living conditions and/or medical needs of prisoners, but it should also look in terms of understanding the psychological variables that might lead to social progress and improvement in the quality of life of prisoners. In this context, the present study examines the roles of loneliness and social support on psychological wellbeing of awaiting-trial inmates in Enugu Prison Command. Psychological well-being is a potential parameter of measuring overall health and good life of a person [31, 7]. It has been observed that poor psychological well-being is associated with deficiency in problem-solving, higher levels of stress and depression, lack of success and the existence of emotional problems [25, 34] excessive alcohol and drug usage [37]. This could be an indication that absence of psychological well-being among prisoners may reflect in inmates' expression of anger, depression and frustrations, which may cause a decrease in the levels of their happiness and satisfaction.

Loneliness and Social Support on Psychological WellBeing is conceptualized as a condition of existence characterized by optimum health. It is a state in which an individual experiences a sense of autonomy, competence, self acceptance, belongingness, purpose and personal growth [10, 28]. Studies [18] indicate three aspects of psychological wellbeing, evaluative well-being - involving global assessments of how people evaluate their satisfaction in life; affective or hedonic well-being - involving measures of feelings such as happiness, sadness and enjoyment; and eudemonic wellbeing - which focuses on judgments about the meaning or purpose of one's life and appraisals of constructs such as fulfillment [18]. Psychological well-being contributes most to a well lived life. It is the positive social relationships, ability to cope in stressful environment, wisdom, sense of meaning and purpose in life $[9,24]$. Psychological well-being is also seen as a contentment and satisfaction (in the past), flow of happiness (in the present) and hope, optimism (for the future) [5]. The role of individual's adaptability, social support networks and connections are fundamental factors to achieving a prisoner's health and psychological well-being. If prisoners are not able to maintain their psychological health, they experience diminished motivation and decline in wellbeing [8].

Social relationship is essential to psychological well-being; that is, personal health and happiness. An individual's ability to enjoy close relationship with others is one of the most important features of healthy personality $[9,31]$. A lack in connection to others may lead to feelings of loneliness and poor psychological well-being. Loneliness is a complex and usually unpleasant emotion which typically includes anxious feelings about a lack of connectedness or communality with others. Loneliness is a common human experience that can affect a wide range of people although some people are at a greater risk of it than others. Loneliness, feeling lonely or being alone had often been used interchangeably [19], but these terms are not exactly the same. For instance, it is possible to feel lonely in the midst of people or in a crowd or to feel socially connected when alone [38-39]. Loneliness is as a result of complex set of feelings encompassing reactions to the absence of intimate and social needs. It is an emotional state in which a person experiences strong feelings of emptiness and social isolation [26, 36]. Loneliness is detrimental to psychological well-being and has a deleterious effect on various aspects of health [14, 23].

Loneliness is composed of negative emotions; a lonely individual feels socially frustrated, feelings of nobody to count on for support, absence of social network and lack of sense of social belongingness. Studies $[12,4,22]$ show that loneliness has detrimental effects on the physical and mental health of the individual. Loneliness places individuals at risk of physical ailments, such as poor cardiovascular health and impaired immune responses [12]. Loneliness is also associated with mental health issues such as, psychosis, personality disorders, impaired cognitive functioning, low self-esteem and depression [2-3]. Particular concern is the correlation between loneliness and suicide or suicidal ideation. Stravynski and Boyer [33] found that people who reported feeling distress about being alone were more likely to have suicidal thoughts and attempts suicide. Generally, research seems to show that loneliness is associated with poor psychological well-being. In a study consisting of American adolescents, [22] found that depressed loneliness was associated with global dissatisfaction not only in social relations, but also in school, work and many facets of life. In school, loneliness was associated with poor grade, expulsion from school, running away from home, and engaging in delinquent acts such as theft and vandalism. Unlike loneliness, many form of social bonds or integration maintain a sense of connectedness to one's social group resulting in feelings of well-being. Studies [4] have reported that social support/relationship is an essential ingredient for emotional and physical health and/or well-being.

Social support refers to a complex transactional process in which there is an active interplay between a person and his or her support network. Social support has been conceptualized as a 'social fund' from which individuals can draw when they are experiencing a crisis. Social support is seen as support available to an individual through social ties to other individuals, groups, and the larger community [20]. Social support may come from family, friends, teachers, healthcare workers community or any social group or network. These supportive resources include empathy, care, love, trust (emotional support) actual aid in time, money (instrumental support) and information, advice, suggestions (informational support) [41]. Social support plays a key role in how an individual adjusts to a life crisis. It can function as both a problem-focused and emotion-focused coping strategies. Social support helps to promote psychological adjustments. In stressful times, social support helps people to reduce psychological distress such as anxiety, frustrations or other negative feelings. It is a factor that determines people's level of psychological and physical health. People with low social support tend to have poorer psychological health, they suffer from social phobia, depressive symptoms, suicidal ideation and they may take plenty alcohol or they indulge in other 
forms of substance abuse. Studies [15, 21] show that wherever there is poor or lack of social support, there is often a tendency for poor emotional issues, such as low self-esteem or diminished psychological health.

The present study investigates the roles of loneliness and social support on the psychological well-being of awaitingtrial inmates in Enugu Prison Command. Two hypotheses were tested in the study. The first hypothesis proposed that high level of loneliness would lead to poorer psychological well-being. That is, loneliness would negatively predict psychological well-being. The proposal is based on the burgeoning research $[3,12]$, which demonstrate that loneliness is associated with poor psychological well-being. Because many awaiting-trial inmates are in social isolation, where the inmate have no social network and really do not have anyone or set of friends, the individual's psychological well-being of that individual would most likely be poor. The second hypothesis examined in this study is that high level of social support would lead to a healthy psychological wellbeing. That is, the hypothesis proposes that social support would positively predict psychological well-being. The present proposal is based on the stress buffering hypothesis; the proposal states that in the event of a stressful experience, those who have social support will suffer less from the potentially harmful effects of that particular occurrence, thus facilitating adaptation [6]. Awaiting-trial inmates with supportive relationships often have social support act as buffer against the stress of incarceration.

\section{Method}

\subsection{Participants}

The participants for the study consist of three hundred (300) awaiting-trial inmates of Enugu Prison Command, Enugu State, drawn from the awaiting trial section. The participants were $220(73.33 \%)$ male and 80 female (26.66\%) prisons inmates. The ages of the participants ranged between 18 years to 69 years with mean age of 43.5 years, and standard deviations (SD) of 5.21.

\subsection{Instruments}

Three instruments were used for the study. They are the Short-form University of California, Los Angeles Loneliness Scale ((ULS-8)[13], the Multidimensional Scale of Perceived Social Support (MSPSS)[42] and the Psychological Wellbeing Scale (PWB-S)[28].The University of Los Angeles loneliness scale(UCL-8)[13] is a revised short-form measure of loneliness. It was designed to measure one's subjective feelings of loneliness and feelings of social isolation. Some items on the scale include: "I lack companionship", "I am an outgoing person", "People are around me but not with me", etc. The scale consists of 8 statements about loneliness. The response options were on a 4-point Likert scale: 1 (never) to 4 (always).Hays and DiMatteo (1987) stated that the measure has internal consistency coefficient $a$ ranging from .89 to .94 . The UCL-8 was validated in a pilot study with 71 prisons inmates in Nsukka Prisons Command. The results indicated a reliability coefficient (Cronbach's alpha) of .81 for the scale. Also, the scale showed a construct validity index of .73.

The scale for measuring social support - the multidimensional scale of perceived social support (MSPSS) [42], comprised of 12 items. The response options followed a 7-point Likert-type scale, ranging from very strongly disagree (1) to very strongly agree (7). Items were divided into three sub-groups, consisting of four items each that relate to the sources of the social support; family, friends and significant others. Items 3, 4, 8 and 11 measures family support; items 6, 7, 9 and 12 measures friend support while items 1, 2, 5 and 10 measures significant other support.Some samples of the items on the MSPSS are: "Tried to step back from situation and be more objective" (family support), "Talked with spouse or other relative about the problem" (friend support), "Discussed feelings with others" (other support), etc. The scale has good reliability indexes: full scale is .85; family sub-scales is .87 ; friends sub-scale is .85 and significant other sub-scale is .91. The pilot study conducted as described above; show Cronbach alpha as follows: full scale .70; sub scales: family .62, significant others .91 and friends .70 .

Psychological well-being scale (PWB-S) [28], is a structured, self-report instrument based on the six dimensions of psychological well-being: Autonomy, environmental mastery, personal growth, positive relationships with others, purpose in life and self-acceptance. The scale is 18 -item scale. Each item is responded using a 5-point Likert scale format. For example, (1) strongly disagree to (5) strongly agree. The psychometric properties of the six dimension of PWB-S range from .86 to .93 [28]. Some items on the scale are: "I tend to be influenced by people with strong opinion", "I am quite good at managing the many responsibilities of my daily life", "I sometimes feel as if I have done all there is to do in life", etc. Some of the items are reversely scored: 1, 5, 9, 10, $12,13,15,18$. The scale was revalidated by the researcher using 71 prisoners from Nigerian prison Nsukka. The reliability analysis of the pilot study show Cronbach's alpha of self acceptance .72 , positive relations .50 , autonomy .46 , environmental mastery .60 , purpose in life .62 and personal growth .57 . Also, the reliability coefficient of the composite variables is .87 .

\subsection{Procedure}

Permission for the research was obtained from the Comptroller of Enugu Prison Command, who gave permission for the study to go on. Three prison staffs (Prison Wardens) were instructed by the Comptroller to superintend the exercise and assist the researchers to talk to the awaitingtrial prisoners. At the venue of the study, the researchers explained the purpose of the study and assured the inmates that their responses would be confidential and anonymous. When reasonable rapport was established between the parties, which are between the researchers and the respondents, the researchers gave out the questionnaires to those respondents who indicated interest to participate. Many prisoners 
volunteered to participate in the study and they were all giving the scales to complete. Completed questionnaires were collected from 351 prison inmates, but during the analysis, only 300 questionnaires were analyzed. The rest were disregarded due to multiple responses on a single item and/or other anomalies.

\subsection{Design/Statistics}

The research employed a cross sectional design. The multiple regression and correlation (MRC) analysis was used to analyse the data.

\section{Results}

Table 1. Multiple regression table showing Beta ( $\beta$ ) coefficient and significant levels of loneliness and social support as predictors of psychological well-being among awaiting-prisons inmates.

\begin{tabular}{llllll}
\hline & Variables & B & Std. Error & Beta $(\boldsymbol{\beta})$ & t \\
\hline 1. & Loneliness & .262 & .064 & .234 & $4.07^{* *}$ \\
2. & Social support & .634 & .245 & .149 & $2.59^{*}$ \\
\hline
\end{tabular}

Key: ** $\mathrm{P}<.001 ; * \mathrm{P}<.05$

The descriptive statistics for the study variable show that loneliness was positively associated with psychological wellbeing $(\mathrm{r}=.20, \mathrm{p}<0.01)$, as well as with social support $(\mathrm{r}=.22$, $\mathrm{p}<0.01)$. Social support was not associated with the criterion variable - psychological well-being. Table 1 show the multiple regression model of the roles of loneliness and social support on psychological well-being. First, the results show that loneliness significantly (and positively) predicted psychological well-being in awaiting-trial inmates of Enugu Prison Command $(\beta=.23, \mathrm{t}=4.07, \mathrm{p}<0.001)$. This result failed to support the stated hypothesis that loneliness would negatively predict psychological well-being. Similarly, the result also show that social support significantly (and positively) predicted psychological well-being in awaitingtrial inmates of Enugu Prison Command $(\beta=15, \mathrm{t}=2.59, \mathrm{p}$ $<0.05)$. The results suggest that that the more social support the better the psychological well-being of awaiting-trial inmates. This result supports the second hypothesis that social support would positively predict psychological wellbeing in awaiting-trial inmates.

In summary, the above results show that the two predictor variables - loneliness and social support, were both positive predictors of the criterion variable - psychological wellbeing. The positive prediction of loneliness on psychological well-being led to the rejection of the first hypothesis, which proposed that loneliness would negatively predict psychological well-being of awaiting-trial inmates. Again, the positive prediction of social support on psychological well-being supported the second hypothesis. The hypothesis maintains that social support would positively predict psychological well-being of awaiting-trial inmates. These results were re-stated and interpreted in the discussion section below.

\section{Discussion}

The present study investigates the roles of loneliness and social support on the psychological well-being of awaitingtrial inmates in Enugu Prison Command. Two hypotheses were proposed. The first hypothesis stated that loneliness would negatively predict psychological well-being of inmates. The results of data analyses show that loneliness predicted psychological well-being. However, the result did not support the hypothesis because the nature of the prediction was positive, instead of the negative prediction that was predicted. This finding seems to be inconsistent with previous literature on loneliness [12, 22, 36, 39]. The previous literature on loneliness argue that social isolation leads to negative emotions which seem to have deleterious effect on an individual's psychological well-being. Although the present finding looks more like a contradiction to past finding, it is not. The finding should rather be interpreted as a contrast to previous findings instead of a contradiction to them. The point is that contrary to public opinion that prison inmates are lonely because they are isolated from the society; the truth is that they are not in solitary isolation, they make friends with fellow inmates and they bond together. The reality of the matter is that many awaiting-trial inmates are recidivists, who come out from prison and do the same thing all over again, and then return back to prison. This 'revolving door' explains why fifty percent of all serious crimes are committed by about five percent of the criminals. Prison inmates have no constructive way to spend their time, so they form network of friends inside the prison, which was why the prison has been described as 'school for criminals'. That is, prison inmates who started off with petty crime frequently graduate into hardened criminals.

The second hypothesis examined in this study is that social support would positively predict psychological well-being. The results of data analyses showed this hypothesis to be true. The finding is consistent with previous literature $[11,15,21$, 32], which observed that high levels of social support tends to lead to high psychological well-being. Although the present finding is consistent with the stated hypothesis, one would have expected awaiting-trial inmates to score low on the multidimensional scale of perceived social support (MSPSS) because of their travails. However, because of some the circumstances mentioned above, awaiting-trial inmates bond together and support each other. Prison inmates often view imprisonment as initiation rite; the prison (school of criminals) trains inmates to graduate into very menacing, mean and violent criminals. As with regular schools, inmates do not ordinarily feel lonely or alone, neither do they lack supportive resources from their fellow inmates, who offer them emotional, instrumental, appraisal and informational supports.

One important implication of the present study is in the renewed interest people have expressed about the effectiveness of the prison to influence a prisoner's behaviour. The four principal reasons for establishing the prison institution are not been met and the government should be 
bothered that prison inmates, rather than turning into new leaf in prison graduates into the worst kind of criminal. This study points to the importance of looking at some of the psychosocial variables that the government may manipulate to impact on a prisoner's behaviour. In relation to loneliness, the government needs to expand the space in prison to ensure that inmates stay separately in solitary confinement. Solitary isolation, when strictly enforced would engender negative emotions in prison inmates and would also not create room for friendship relationship to develop. This practice will discourage recidivism as the prison would truly be a place to punish offenders. Also, there is need to provide vocational training facilities and other social services in the prison so that prison inmates would have constructive way to spend their time. It is again expected that engaging them in these activities would leave them no time to form bonds or provide support for one another.

The present study is limited by the non-experimental design that was adopted. The conclusions reached in this study would have been more robust if experimental method was used to test for differences between awaiting-trial inmates who are lonely and others who are not, and between awaiting-trial inmates who have social support and others who have none, to see how they differed from each other. In other to replicate this study with this later method, the researchers recommend that future studies in this area should use the experimental method of data collection in the study.

\section{Conclusion}

The present study examined the roles of loneliness and social support on psychological well-being of awaiting-trial inmates in Enugu Prison Command. Two hypotheses were proposed. The hypotheses were that first, loneliness would negatively predict psychological well-being in awaiting-trial inmates and secondly, that social support would positively predict psychological well-being in awaiting-trial inmates. Three instruments, namely: the short-form University of California, Los Angeles loneliness scale (ULS-8)[13], the multidimensional scale of perceived social support (MSPSS) [42] and the psychological well-being scale (PWBS)[28]were used for data collection. The design employed in the study was cross-sectional design and the multiple regression and correlation (MRC) was used to analyze the data gathered in the study. Results of that analyses show that both loneliness and social support significantly predicted psychological well-being in awaiting-trial inmates of Enugu Prison Command. The results failed to support the first hypothesis, but supported the second hypothesis. These results were discussed. The application suggested was that the government and other stakeholders need to engage prisoners in meaningful activities, so that inmates should have less time to bond together and/or provide support for one another. The limitation of the study and recommendation for future research was stated.

\section{References}

[1] Abiama, E.E., \& Etowa, P.E. (2013). "The impact of longterm incarceration and solitary confinement on the mental health of prison inmates in Nigeria". Nigerian Journal of Psychological Research, 9, 28-37.

[2] Benner, A. D. (2011). "Latino adolescents' loneliness, academic performance and the buffering nature o friendships". Journal of Youth and Adolescence, 40, 556-567.

[3] Besevegis, E., \& Galanaki, E. P. (2010). "Coping with loneliness in childhood". European Journal of Developmental Psychology, 7, 653-673.

[4] Cacioppo, J. T., \& Hawkley, L.C. (2003). "Social isolation and health with emphasis on underlying mechanism". Perspectives in Biology and Medicine, 46, 39-52.

[5] Carr, A. (2004). "Positive psychology: The science of happiness and human strengths". New York: BrunnerRoutledge.

[6] Cohen, S., \& Wills, T. A. (1995). "Stress, social support and the buffering hypothesis". Psychological Bulletin, 98, 310-357.

[7] Cooper, C., \& Berwick, S. (2001). "Current psychology, development, learning, personality". Social Summer, 20 (2), 169-182.

[8] Deci, E. L., \& Ryan, R. M. (2008). "Facilitating optimal motivation and psychological well-being across life's domains". Canadian Psychology, 49, 14-23.

[9] Diener, E. (2009). "Subjective well-being". In E. Diener, (ed.), The science of well-being. London: Office for National Statistics.

[10] Fava, G. A., \& Ruini, C. (2003). "Development and characteristics of a well-being. Enhancing psychotherapeutic strategy: Well-being therapy". Journal of Behaviour Therapy and Experimental Psychiatry, 34, 45-63.

[11] Haney, C. (2002). "The psychological impact of incarceration: Implication for post prison adjustment". http://aspe.hhs.gov/hsp/prisons2home/haney.pdf. Assessed on May $17^{\text {th }} 2013$.

[12] Hawkley, L. C., \& Cacioppo, J. T. (2010). "Loneliness matters: A theoretical and empirical review of consequences and mechanisms". Annuals of Behavioural Medicine, 40, 218-227.

[13] Hays, R. D., \& Di Matteo, M. R. (1987). "A short-form measure of loneliness". Journal of Personality Assessment, 51, 69-81.

[14] Heinrich, L. A., \& Gullone, E. (2006). "The clinical significance of loneliness: A literature review". Clinical Psychology Review, 26, 695-718.

[15] Huang, M., Yen, C., \& Lung, F. (2010). "Moderators and mediators among panic, agoraphobia symptoms, and suicidal ideation in patients with panic disorder". Comprehensive Psychiatry, 51, 243-249. Doi: 10.1016/j.comppsych.2009.07.005.

[16] Igboeli, C. I. (1994). "Stress manifestation in prisoners in Nigeria". Unpublished Master's Degree Thesis, University of Jos, Jos Nigeria. 
[17] Jones, W., Rose, J., \& Russell, D. (1990). Loneliness and social anxiety. In H. Leitenberg (Ed.). "Handbook of social and evaluation anxiety". New York: Plenum Press.

[18] Kahneman, D., \& Deaton, A. (2010). "High income improves evaluation of life but not emotional well-being', Proceedings of the National Academy of Sciences of the United States of America, 107, 1689-1693.

[19] Karnick, P. M. (2005). "Feeling lonely: Theoretical perspectives". Nursing Science Quarterly, 18, 7-12.

[20] Lakey, B., \& Cronin, A. (2008). Low social support and major depression: Research, theory, and methodological issues. In K.S., Dobson \& D. Dozois. "Risk factors for depression". Academic Press (pp. 385-408).

[21] Lechner, L., Bolman, C., \& Van Dalen, A. (2006). "Definite involuntary childlessness: Associations between coping, social support, and psychological distress". Human Reproduction, 22 (1), 288-294.

[22] Martina, C.M.S., \& Stevens, N.L. (2006). "Breaking the cycle of loneliness: Psychological effects of a friendship enrichment program for older women". Ageing and Mental Health, 10 (5), 467-475.

[23] Murphy, P. M., \& Kupshik, G.A. (1992). "Loneliness, stress and well-being: A helper's guide”. New York: Routledge.

[24] Myers, D.G. (1992). “The pursuit of happiness”. New York: Avon.

[25] Myers, E. J., Sweeney, T. J., \& Witmer, J. M. (2004). "The Wheel of Wellness, Counselling for Wellness: A holistic model for treatment planning". Journal of Counselling \& Development, 78, 251-266.

[26] Rokach, A., \& Brock, H. (2012)."Coping with loneliness". Journal of Psychology, 132 (1), 107-121.

[27] Ryan, R. M., \& Deci, E. L. (2001). "On happiness and human potential: A review of research on hedonic and eudemonic well-being". Annual Review of Psychology, 52, 141-166.

[28] Ryff, C. D. (1995). "Psychological well-being in adult life". Current Directions in Psychological Science, 4 (4), 99-104.

[29] Sanderson, C. A. (2004). "Health psychology". Hoboken: John Wiley.
[30] Seligman, M. E. P. (2008). "Positive health". Applied Psychology: An International Review, 57, 3-18.

[31] Seligman, M. E. P., \& Csikzentmihalyi, M. (2000). "Positive psychology". American Psychologist, 55 (1), 5-14.

[32] Shuker, R., \& Newton, M. (2008). "Treatment outcome following interventions in a prison based therapeutic community: A study of the relationship between reduction in criminogenic risk and improved psychological well-being". British Journal of Forensic Practice, 10, 33-45.

[33] Stravynski, A., \& Boyer, R. (2001). "Loneliness in relation to suicide ideation and parasuicide: A population-wide study". Suicide and Life-Threatening Behaviour, 31 (1), 32-40.

[34] Temane, Q. M., \& Wissing, M.P. (2006). "The role of subjective perception of health in the dynamics of context and psychological of health in the dynamics of context and psychological well-being". South African Journal of Psychology, 36 (3), 564-581.

[35] United Nations Development Programme (UNDP) (2015). "Human development report". New York: Author.

[36] Victor, C. R., Bowling, C. R., \& Bond, J., (2002). "Loneliness, social isolation and living alone in later life". Sheffield: ESRC.

[37] Visser, M., \& Routledge, L. (2007). "Substance abuse and psychological well-being of South African adolescents". South African Journal of Psychology, 37 (3), 595-615.

[38] Weeks, M. S. (2010). "Loneliness and belongingness in childhood, adolescence, and young adulthood: An integrative review". Unpublished Master's Thesis, Duke University, North Carolina.

[39] Weeks, M. S., \& Asher, S. R. (2012). "Loneliness in childhood: Toward the next generation of assessment and research". Advances in Child Development and Behaviour, 42, $1-40$.

[40] Yasin, A., \& Dzuikifli, M. A. (2010). "The relationship between social support and psychological problem among students". International Forum of Business and Social Science, 1, 3-11.

[41] Zimet, G. D., Dahlem, N. W., Zimet, S. G., \& Farley, G. K. (1988). "The multidimensional scale of perceived social support”. Journal of Personality Assessment, 52, 610-617. 